\title{
Complications of sclerotherapy for 75 head and neck venous malformations
}

\author{
Pitkäranta, Anne Irene
}

2016

Pitkäranta , A I , Salminen , P , Vuola , P , Lappalainen , K, Pekkola , M J , Klockars , T K M , Aronniemi , J \& Castren , E 2016 , ' Complications of sclerotherapy for 75 head and neck venous malformations ' , European Archives of Oto-Rhino-Laryngology , vol. 2016 , no. 4 , pp. 1027-1036 . https://doi.org/10.1007/s00405-015-3577-x

http://hdl.handle.net/10138/223845

https://doi.org/10.1007/s00405-015-3577-x

publishedVersion

Downloaded from Helda, University of Helsinki institutional repository.

This is an electronic reprint of the original article.

This reprint may differ from the original in pagination and typographic detail.

Please cite the original version. 


\title{
Complications of sclerotherapy for $\mathbf{7 5}$ head and neck venous malformations
}

\author{
Eeva Castrén · Johanna Aronniemi - Tuomas Klockars • \\ Johanna Pekkola $\cdot$ Kimmo Lappalainen $\cdot$ Pia Vuola $\cdot$ \\ Päivi Salminen • Anne Pitkäranta
}

Received: 14 November 2014/Accepted: 23 February 2015/Published online: 4 March 2015

(C) Springer-Verlag Berlin Heidelberg 2015

\begin{abstract}
Sclerotherapy is one treatment option for head and neck venous malformations (VMs). Evaluation of complication risks is, however, essential to improve its safety. We aimed to systematically report sclerotherapy complications by means of the Clavien-Dindo classification and to distinguish factors predisposing to complications. We identified our institution's head and neck VM patients who received sclerotherapy between 1 January 2007 and 31 August 2013, analyzed patient reports retrospectively, and applied to them the Clavien-Dindo classification. Our $75 \mathrm{VM}$ patients underwent a total of 150 sclerotherapy sessions. The most common sclerosants were $3 \%$ sodium tetradecyl sulfate and polidocanol. Complications occurred in 13 patients $(17.3 \%)$ and in 15 sessions $(10.0 \%)$; 3 complications required extensive postprocedural treatment and caused permanent morbidity, whereas 12 received conservative treatment. Patients with sclerotherapy complications underwent more treatments
\end{abstract}

E. Castrén $(\bowtie) \cdot$ T. Klockars · A. Pitkäranta

Department of Otorhinolaryngology-Head and Neck Surgery, Helsinki University Central Hospital and University of Helsinki, P.O. Box 220, 00029 HUCH Helsinki, Finland

e-mail: eeva.castren@helsinki.fi

J. Aronniemi · J. Pekkola $\cdot$ K. Lappalainen

Department of Radiology, HUS Medical Imaging Center, Helsinki University Central Hospital and University of Helsinki, Helsinki, Finland

P. Vuola

Department of Plastic Surgery, Helsinki University Central

Hospital and University of Helsinki, Helsinki, Finland

P. Salminen

Department of Pediatric Surgery, Children's Hospital, Helsinki University Central Hospital and University of Helsinki, Helsinki, Finland $(p=0.009)$ and more often needed further surgery $(p=0.007)$. We thus consider sclerotherapy a relatively safe treatment modality for head and neck VMs. To avoid complications, evaluation of VM characteristics and optimal treatment technique in a multidisciplinary team is vital.

Keywords Clavien-Dindo classification · Safety · Treatment · Vascular anomaly

\section{Introduction}

Venous malformations (VMs) are benign vascular anomalies comprising dilated vascular channels lined with endothelial cells [1]. Their estimated prevalence is 1 per 5000 to 10,000 individuals [2]. Most VMs are sporadic, but some familial forms exist [3, 4]. Approximately $40 \%$ of VMs appear in the head and neck region [5-7], commonly in the cheek or lips [8]. The phenotype ranges from small focal lesions to diffuse complex masses disturbing various tissues and vital structures. VMs often occur in subcutaneous or submucosal tissue, but may involve muscle, bone, or the viscera. Some cervicofacial VMs are associated with intracranial vessels [9].

VMs are congenital but may progress with age, leading to clinical symptoms. VMs never regress. Growth acceleration may occur after trauma or occur during puberty and pregnancy, because VMs react to hormonal changes [1]. Symptoms of head and neck VMs typically manifest during physical exercise and are position dependent. Symptom severity ranges from mild to life-threatening; manifestations include swelling, skin discoloration, painful phlebothrombosis, asymmetry, speech impairment, nerve compression, exophthalmos, bleedings, coagulopathy, and airway obstruction [1]. 
Due to the delicate anatomy involved and the functional demands, treatment of head and neck VMs constitutes a multidisciplinary challenge. Surgery, laser therapy, and sclerotherapy are potential treatments for VMs. Sclerotherapy aims to destroy the vascular walls, leading to malformation shrinkage [1]. Before the development of sclerotherapy, surgery was virtually the only treatment modality for VMs. Surgery remains the primary or an adjuvant option for some lesions, but diffuse VMs remain inoperable [5, 10-13]. Laser therapy can serve for some lesions [14, 15].

Although sclerotherapy is minimally invasive and often safe $[8,16]$, complications ranging from mild skin ulcerations to nerve injuries, tissue necrosis, gross hemoglobinuria, blood coagulation problems, pulmonary hypertension, and even lethal pulmonary embolism do occur $[8,17-20]$. Because sclerosants and interventional techniques differ in safety and efficacy, identification of factors predisposing to complications is mandatory. Choice of optimal treatment modality for each VM patient demands multidisciplinary assessment; the treatment's potential risks should not exceed the morbidity resulting from the VM.

Systematic reporting and monitoring of complications improves treatment quality. The Clavien-Dindo classification, widely applied in evaluating complications of surgery (Table 1), was first proposed in 1992 and modified in 2004 to better serve clinical assessment [21-23]. It objectively grades the additional procedures required to treat any complications. To our knowledge, no other institution has applied this classification in reporting sclerotherapy complications.

This study aims to systematically analyze our institution's sclerotherapy complications for head and neck VMs with the Clavien-Dindo classification. Our objective is to determine patient characteristics and treatment features that predispose to sclerotherapy complications.

\section{Materials and methods}

\section{Literature}

Our PubMed search utilized as keywords "venous malformation", "sclerotherapy", and "head", "neck" or "craniofacial". The query returned 81 articles, 69 of which were in English. We assessed these and related articles acquired by cross-referencing.

\section{Helsinki University Central Hospital}

Helsinki University Central Hospital ( $\mathrm{HUCH})$ is a tertiary referral center that provides healthcare services for 1.5 million inhabitants in southern Finland. HUCH also receives referral patients from other hospital districts in Finland. HUCH founded a multidisciplinary team (MDT) in 2002 for the treatment of vascular anomalies. Our MDT comprises physicians from the disciplines of otorhinolaryngology, pediatrics, maxillofacial, plastic, and craniofacial surgery, dermatology, ophthalmology, diagnostic and interventional radiology, and pathology.

\section{Patients}

The study protocol was approved by the Ethics Committee of Helsinki University Central Hospital. We identified patients treated with sclerotherapy for head and neck VM between 1 January 2007 and 31 August 2013 from the

Table 1 Classification of surgical complication according to Clavien-Dindo [21]

\begin{tabular}{|c|c|}
\hline Grade & Definition \\
\hline I & $\begin{array}{l}\text { Any deviation from the normal postoperative course without pharmacological treatment or surgical, endoscopic, and radiological } \\
\text { interventions. Acceptable therapeutic regimens are antiemetics, antipyretics, analgetics, diuretics, and electrolytes, and } \\
\text { physiotherapy. This grade includes wound infections opened at the bedside }\end{array}$ \\
\hline II & $\begin{array}{l}\text { Requiring pharmacological treatment with drugs other than those allowed for grade I complications. Blood transfusions and total } \\
\text { parenteral nutrition are also included }\end{array}$ \\
\hline III & Requiring surgical, endoscopic, or radiological intervention \\
\hline IIIa & Intervention not under general anesthesia \\
\hline $\mathrm{IIIb}$ & Intervention under general anesthesia \\
\hline IV & $\begin{array}{l}\text { Life-threatening complication (including central nervous system complications) }{ }^{\mathrm{a}} \text { requiring Intermediate care or Intensive care unit } \\
\text { management }\end{array}$ \\
\hline IVa & Single-organ dysfunction \\
\hline $\mathrm{IVb}$ & Multi-organ dysfunction \\
\hline $\mathrm{V}$ & Death of a patient \\
\hline $\begin{array}{l}\text { Suffix } \\
\text { 'd' }\end{array}$ & $\begin{array}{l}\text { If the patient suffers from a complication at the time of discharge, the suffix 'd' (for 'disability') is added to the respective grade of } \\
\text { complication. This label indicates the need for a follow-up to fully evaluate the complication }\end{array}$ \\
\hline
\end{tabular}

${ }^{a}$ Brain hemorrhage, ischemic stroke, subarachnoidal bleeding, but excluding transient ischemic attacks (Tia) 
electronic radiology information system. We based VM diagnosis on clinical evaluation, MRI, and ultrasound imaging according to the International Society for the Study of Vascular Anomalies classification [24]. We recorded VM patients' demographic details, lesion location, and tissue involvement according to imaging studies, possible previous surgery, number of sclerotherapy sessions, sclerosants, perioperative corticosteroid administration, adjuvant surgery, and complications. Sclerotherapy outcome was recorded retrospectively at the time of this research (December 2013). Outcome was either satisfactory if the patient was satisfied and asymptomatic without receiving any other treatments after sclerotherapy, or unsatisfactory if the symptoms persisted despite sclerotherapy with no other treatment modalities available. We also recorded the patients receiving ongoing sclerotherapy and those receiving other treatments due to insufficient sclerotherapy result. Follow-up was recorded from the first and last sclerotherapy session to the time of the current study. Based on MDT consensus, the grade for each complication was set according to the Clavien-Dindo classification. We grouped VM location into lower face, mid-face, upper face, neck, oral cavity, orbit, or a combination of these. VM tissue invasion was divided into subcutaneous, submucosal, intramuscular, intraosseal, or a combination of these.

\section{Sclerotherapy procedure}

Indications for sclerotherapy included pain, functional impairment, or disturbing facial asymmetry. An interventional radiologist performed the sclerotherapy. Patients with small, superficial VMs and capable of sufficient cooperation received the treatment under local anesthesia and conscious sedation. For VMs in delicate or painful areas, the treatment was under general anesthesia.

At sclerotherapy, the lesion was first cannulated with one or several needles under ultrasound guidance, and retrograde blood flow confirmed intravenous access. Lesion architecture and draining veins were assessed fluoroscopically with iodinated contrast injection. If the venous drainage was rapid or flowed through potentially critical routes, the draining veins were compressed or mechanically blocked. We mainly used a draining technique in which we injected the sclerosant through one needle and let blood and excessive sclerosant drain out from other needles elsewhere in the lesion to prevent overfill and ensure the draining of the whole lesion with the sclerosant.

Sclerosants were mainly foam detergents of $3 \%$ sodium tetradecyl sulfate (STS) or polidocanol $(5-30 \mathrm{mg} / \mathrm{ml})$ (Aethoxysklerol®) and rarely bleomycin $(1 \mathrm{mg} / \mathrm{ml}), 95 \%$ ethanol, doxycyclin, or a combination of these. STS was the first-line choice. Polidocanol, being available in various concentrations, served for small superficial lesions.
Bleomycin, an anti-cancerous antibiotic, was preferred if swelling was especially undesirable. Ethanol, used rarely and applied as sole treatment only in 2007, was later injected as part of combination therapies for extensive lesions responding poorly to other sclerosants. When extensive swelling after sclerotherapy was expected or when the lesion's location was anatomically confined, we gave a perioperative corticosteroid. To further diminish tissue swelling and to promote closure of the vascular channels, the patients, if suitable, wore a compressive textile after the treatment.

We tailored treatment to each VM patient individually. Patients with large lesions or VMs near the airways remained in hospital overnight. Other VM patients with minor postprocedural swelling and pain were monitored for 2 or $3 \mathrm{~h}$ and then discharged. All patients were advised to contact the hospital in case of complications. We scheduled several sclerotherapies in series for extensive VM lesions. Most patients were clinically followed for 1-3 months after sclerotherapy. If their response was satisfactory, they contacted our clinic only in case of recurrence. If symptoms persisted despite repeated sclerotherapies, the MDT evaluated the possibilities of other treatment modalities.

\section{Statistics}

An independent statistician performed all statistical calculations (Datawell Oy, Espoo, Finland). Microsoft Office Excel 2007 and NCSS8 Statistical Software were applied for data analysis. Logistic regression analysis was performed for variables predicting complications with the Fisher and the Mann-Whitney tests, with a $p$ value of $<0.05$ considered statistically significant.

\section{Results}

Table 2 summarizes characteristics of the 75 patients in the study, their sclerotherapy procedures (mean 2 per patient, range 1-13), and other key data. Patients with a small lesion that was expected to resolve with only one treatment were not always clinically followed up. Additionally, those patients who failed to attend the follow-up were monitored from hospital records. Of the 75 patients, 22 continued to receive sclerotherapy or other treatments at the time of this research. Sclerotherapy outcome for patients without complication was satisfactory in $72.6,16.1 \%$ continued receiving sclerotherapy, $6.5 \%$ received other treatments due to insufficient sclerotherapy outcome, $1.6 \%$ claimed an unsatisfactory outcome with no other treatment modalities, and $3.2 \%$ were lost from follow-up. Of the patients with complications, $38.5 \%$ had a satisfactory and $7.7 \%$ an unsatisfactory sclerotherapy outcome, $15.4 \%$ received 
Table 2 Venous malformation (VM) patients' demographic and session details, and location and tissue involvement of the VM

\begin{tabular}{|c|c|c|c|}
\hline Demographics and sessions & Total $(n=75)$ & No complication $(n=62)$ & Complication $(n=13)$ \\
\hline Patients & 75 & $62(82.7 \%)$ & $13(17.3 \%)$ \\
\hline Sclerotherapy sessions & 150 & $135(90.0 \%)$ & $15(10.0 \%)$ \\
\hline Female/male & $51(68.0 \%) / 24(32.0 \%)$ & $42(67.7 \%) / 20(32.3 \%)$ & $9(69.2 \%) / 4(30.8 \%)$ \\
\hline Age at first sclerotherapy (mean/median) & $35.9 / 33.0$ & $37.2 / 36.5$ & $29.8 / 23.0$ \\
\hline Session per patient (mean/median) & $2.0 / 1.0$ & 1.7/1.0 & $3.3 / 2.0$ \\
\hline Surgery prior to/after sclerotherapy & $27(36.0 \%) / 6(8.0 \%)$ & $23(37.1 \%) / 2(3.2 \%)$ & $4(30.8 \%) / 4(30.8 \%)$ \\
\hline Perioperative corticosteroid & $64(42.7 \%)$ & $55(40.7 \%)$ & $9(60.0 \%)$ \\
\hline Follow-up 1 (mean/median) & $18.4 / 6.0$ & $16.5 / 5.0$ & 27.3/25.0 \\
\hline Passive follow-up 1 (mean/median) & $44.7 / 50.0$ & $45.6 / 51.0$ & $40.2 / 33.0$ \\
\hline Passive follow-up 2 (mean/median) & $36.5 / 35.0$ & $38.4 / 39.0$ & $27.3 / 24.0$ \\
\hline Patients with ongoing treatments & $22(29.3 \%)$ & $16(11.9 \%)$ & $6(46.2 \%)$ \\
\hline \multicolumn{4}{|l|}{ Location } \\
\hline Neck & $5(6.7 \%)$ & $5(8.1 \%)$ & 0 \\
\hline Lower face & $5(6.7 \%)$ & $5(8.1 \%)$ & 0 \\
\hline Mid-face & $18(24.0 \%)$ & $17(27.4 \%)$ & $1(7.7 \%)$ \\
\hline Upper face & $2(2.7 \%)$ & 0 & $2(15.4 \%)$ \\
\hline Orbital/periorbital & $3(4.0 \%)$ & $2(3.2 \%)$ & $1(7.7 \%)$ \\
\hline Oral cavity & $23(30.7 \%)$ & $17(27.4 \%)$ & $6(46.2 \%)$ \\
\hline Affecting $\geq 2$ regions with orbital connection & $3(4.0 \%)$ & $1(1.6 \%)$ & $2(15.4 \%)$ \\
\hline Affecting $\geq 2$ regions with oral cavity connection & $16(21.3 \%)$ & $15(24.2 \%)$ & $1(7.7 \%)$ \\
\hline \multicolumn{4}{|l|}{ Tissue involvement } \\
\hline Subcutaneous/submucosal & $33(44.0 \%)$ & $30(48.4 \%)$ & $3(23.1 \%)$ \\
\hline Intramuscular & $13(17.3 \%)$ & $10(16.1 \%)$ & $3(23.1 \%)$ \\
\hline Intraosseal & $2(2.7 \%)$ & 0 & $2(15.4 \%)$ \\
\hline Traversing $\geq 2$ tissue planes & $27(36.0 \%)$ & $22(35.5 \%)$ & $5(38.5 \%)$ \\
\hline
\end{tabular}

Follow-up times are given in months. Follow-up 1 is calculated from first session to the last visit. Passive follow-up 1 calculated from the first session and passive follow-up 2 from the last session to December 2013. Lower face: mandible region up to the nasolabial fold; mid-face: from nasolabial fold to the inferior line of the orbit, including the ears; upper face: upwards from the orbit and temporal region. Rows in bold indicate a significant difference $(p<0.05)$

ongoing sclerotherapy, other treatments after sclerotherapy were given to 30.8 , and $7.7 \%$ were lost from follow-up. The follow-up time from the last sclerotherapy to the time of this study was on average 36 months.

We injected sclerosants either alone (119 sessions, $79.3 \%$ ) or in combination (31 sessions, $20.7 \%$ ). STS and polidocanol, applied either alone or in combination, were those most frequently administered (Table 3 ). Injection of ethanol, bleomycin, or doxycyclin was rare.

Complications in sclerotherapy

Complications affected 13 patients $(17.3 \%)$ and complications occurred in 15 sessions $(10.0 \%): 3$ (4.0\% of the patients, $2.0 \%$ of the treatments) were classified as grades III or IV. Ten patients $(13.3 \%)$ experienced complications graded I or II in 12 sessions $(8.0 \%)$. Those patients with complications underwent significantly more sclerotherapy sessions $(p=0.009)$ and needed surgery significantly more often after sclerotherapy than did patients without complications $(p=0.007)$. They underwent a longer active follow-up $(p=0.01)$ than did those without complications; figures for this finding are, however, confounded by the fact that some patients continued to receive treatments.

We noticed no significant difference in complication risk between sclerosants (Table 3). Injection of STS and polidocanol alone was less often for cases with complications than for non-complicated cases. Bleomycin was infrequently applied, but its injection, either alone or in combination, led proportionally more often to complications, as did ethanol when used in combination.

Complications ranged from grades I to IV (Table 4), with no lethal complications. Grade I and II complications resolved with no treatment or with conservative treatment and comprised local mucous necrosis, postoperative infections, recovering nerve palsies, prolonged (more than 2 weeks) or unusual swelling, hematoma, or pain. 
Table 3 Sclerosant agent use. Sclerosants injected in combination may involve several sclerosants in the same session. 150 sessions in total

\begin{tabular}{lllll}
\hline Sclerosant agent & $\begin{array}{l}\text { No complication } \\
(n=110) ; \text { sclerosant } \\
\text { alone }\end{array}$ & $\begin{array}{l}\text { No complication }(n=25) ; \\
\text { sclerosants in combination }\end{array}$ & $\begin{array}{l}\text { Complications }(n=9) ; \\
\text { sclerosant alone }\end{array}$ & $\begin{array}{l}\text { Complication }(n=6) ; \\
\text { sclerosants in combination }\end{array}$ \\
\hline Sodium tetradecyl sulfate & $89(80.9 \%)$ & $13(52.0 \%)$ & $7(77.8 \%)$ & $3(50.0 \%)$ \\
Polidocanol & $16(14.5 \%)$ & $19(76.0 \%)$ & $1(11.1 \%)$ & $3(50.0 \%)$ \\
Bleomycin & $2(1.8 \%)$ & $5(20.0 \%)$ & $1(11.1 \%)$ & $2(33.3 \%)$ \\
$95 \%$ Ethanol & $1(0.9 \%)$ & $5(20.0 \%)$ & 0 & $2(33.3 \%)$ \\
Doxycyclin & 0 & $2(8.0 \%)$ & 0 & 0 \\
Detergent sclerosant, not defined & $2(1.8 \%)$ & 0 & & 0 \\
\hline
\end{tabular}

Three patients each suffered from a severe (grade III or IV) complication.

One healthy 29-year-old woman had a submucosal VM in the palate, provoking episodes of pain before any treatments. At the first sclerotherapy with STS, occlusion of the peripheral vascular bed of the internal maxillary artery in the palatine area occurred, presumably due to sclerosant accidentally entering the artery. This resulted in bone necrosis in the maxilla that required partial surgical removal of the maxillary bone and three teeth all of which had turned necrotic. She now suffers from a permanent bone defect and allodynia. We recorded this as a grade IIIb complication (Table 4; Fig. 1).

One healthy 31-year-old woman presented with a large subcutaneous and intramuscular VM in the temporal region which was connected to intracranial veins, causing episodes of severe headache. After the second sclerotherapy with STS, she developed a peripheral facial nerve palsy, a frontal and temporal skin necrosis, and frontal muscle necrosis. These demanded several revisions and correction with a skin graft. Scar corrections were later necessary, she lost the function of the right frontal muscle, but other functions of the facial nerve recovered. Permanent partial hair loss occurred in the grafted temporal scalp area. We considered this as a grade IIIb complication (Table 4; Fig. 2).

One 69-year-old man with type 2 diabetes and on acetylsalicylic acid medication had a large intramuscular $\mathrm{VM}$ in the tongue, causing functional impairment in eating and speaking. He underwent sclerotherapy with a combination of STS, bleomycin, and ethanol. During the treatment, an unexpected massive bleed from the capillaries occurred. It did not cease with compression and needed catheterization of the right lingual artery and injection of embolizing particles into the capillaries, leading to partial tongue muscle necrosis. The necrotic tissue became infected and led to sepsis, requiring intravenous antibiotics and surgical removal. This resulted in partial loss of the tongue. The patient now suffers from functional articulation problems and pain. We considered this to be a singleorgan dysfunction, thus, a grade IVa complication (Table 4; Fig. 3).

\section{Discussion}

Introduction of sclerotherapy for VMs has modernized the treatment of these challenging vascular lesions [8, 25-27]. We focused on reporting the complications of sclerotherapy because no large studies on detergent sclerosants exist. During our patients' follow-up, sclerotherapy complications affected $17.3 \%$, with a complication rate after each treatment of $10.0 \%$. Most of these patients fully recovered, except three with grade III or IV complications requiring surgery and resulting in permanent morbidity. No systemic or central nervous system complications occurred. Sclerotherapy outcome was satisfactory in $72.6 \%$ of patients without complication, whereas the rate for those with complication was $38.5 \%$. Patients with complications needed surgery significantly more often after sclerotherapy than did those without complication. Patients with complications had more demanding VMs that required significantly more treatments, which increased their risk for complications.

Complication rates in studies of sclerotherapy for head and neck VMs range from 0 to $61.4 \%$, and only limited data exist regarding sclerotherapy complications with detergent sclerosants (Table 5) [8, 25-43]. Most earlier studies applied ethanol sclerotherapy and concentrated on treatment outcome, reporting complications only descriptively. Most adverse effects of sclerotherapy appear during or soon after treatment but few case reports of possible long-term complications exist [44]. In addition, the definition of a treatment complication in sclerotherapy remains ambiguous; some studies consider recovering, local skin and mucous ulcerations or extensive swelling as 


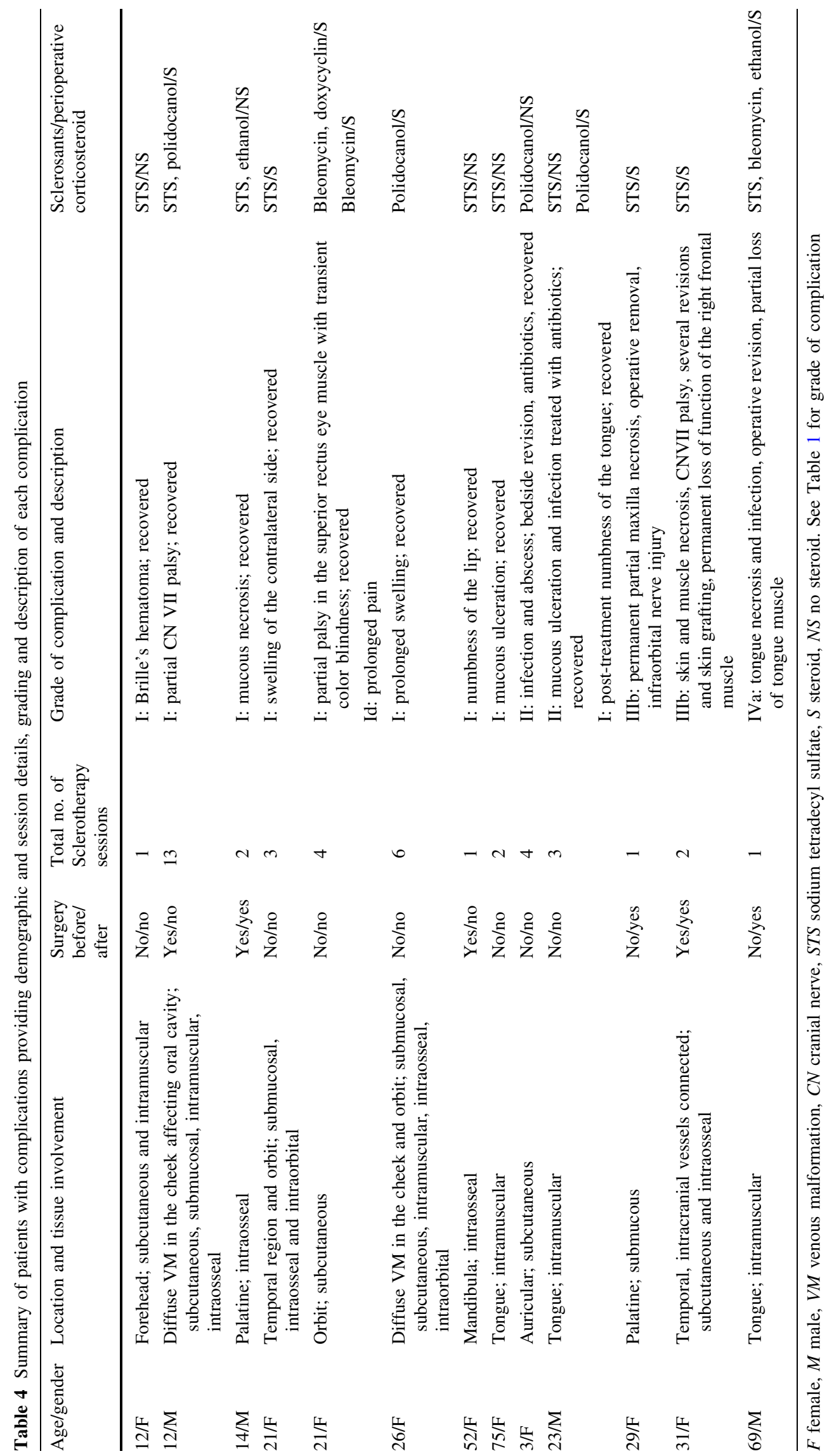




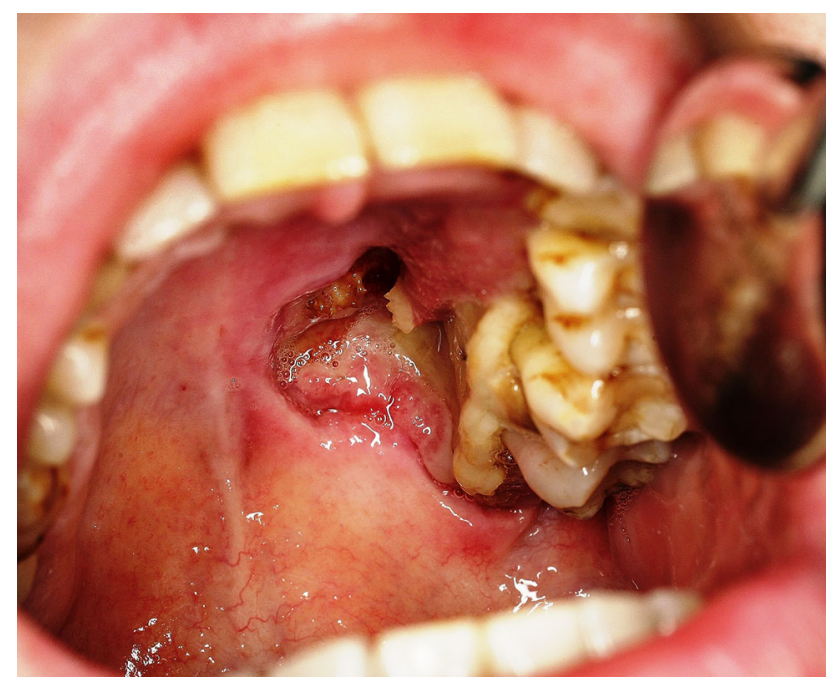

Fig. 1 Clinical image of a patient with a submucosal VM in the palatine after sclerotherapy that led to maxilla and tooth necrosis

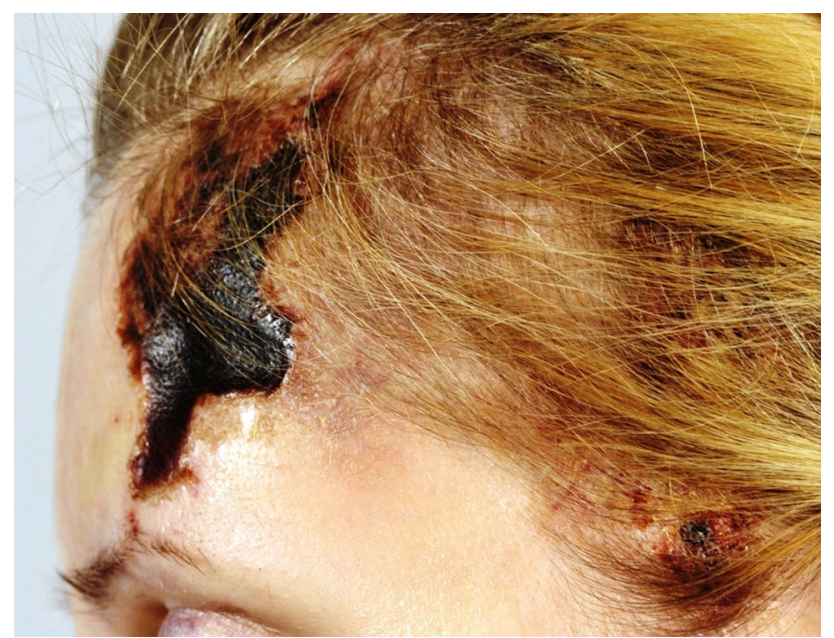

Fig. 2 Clinical image of a patient with a temporal VM penetrating several tissue layers. After sclerotherapy, a large skin and muscle necrosis occurred, requiring several revisions and skin grafting

complications, whereas others consider these to be acceptable treatment side-effects. We reported these adverse effects as complications.

The Clavien-Dindo classification, an objective grading for surgical complications, defines the additional treatment procedures that a complication requires, avoiding the use of the subjective terms "minor" and "major" $[21,22]$. Systematic evaluation of physicians' agreement on grading has rendered this classification transparent and reproducible [23]. The weakness of the Clavien-Dindo classification, in our view, lies in its assessment of a complication as not leading to permanent morbidity when there is no organ dysfunction, or when healing treatment is unavailable. This leads to low grading for nerve injuries and prolonged pain,

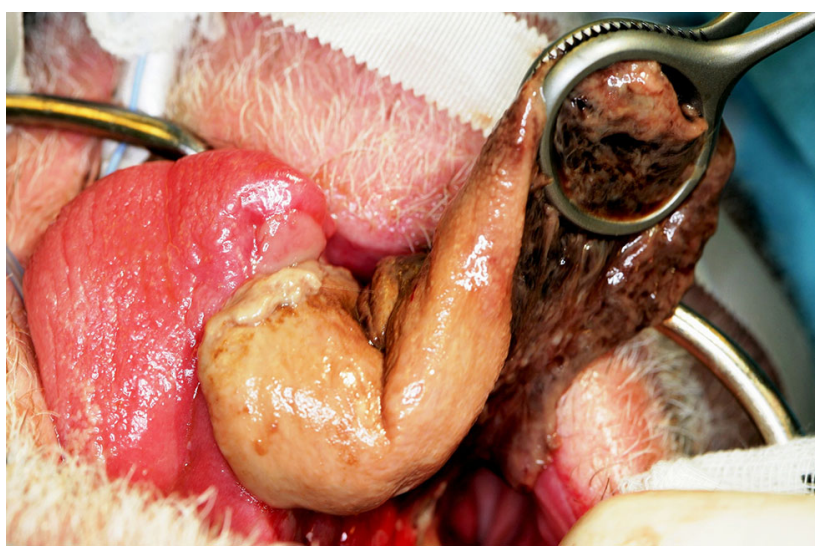

Fig. 3 Clinical image of a patient with an intramuscular VM in the tongue that became necrotic after sclerotherapy and required operative removal of the necrotic tissue

which may nevertheless result in permanent morbidity. Sclerotherapy has partially replaced surgery and may play an adjuvant role, thus requiring equal and objective assessment of complications. Despite the weaknesses of the Clavien-Dindo classification, it allows us to compare the safety of sclerotherapy and of surgery. The Society of Interventional Radiology (SIR) has introduced its own classification for interventional radiology, categorizing adverse effects of minor or major complications as subgroups A to F [45]. However, this classification also somewhat subjectively defines the consequences of a complication.

Before treating VMs with sclerotherapy, evaluation of initial features predisposing a patient to complications is crucial. Manifestations of VMs in our study varied markedly. We had, however, a relatively low number of patients for statistical purposes, leading to difficulty in obtaining significant data on complication risks in relation to lesion location and tissue involvement. We did report somewhat fewer complications in patients with VM in the subcutaneous or submucosal tissue, whereas lesions in the orbit or oral cavity or those penetrating muscle, bone, or several tissue layers developed proportionally more complications. These differences were, however, statistically insignificant (Table 2).

The complication mechanisms in sclerotherapy vary. In general, sclerosant extravasation from the targeted site causes tissue toxicity and may lead to local tissue injury. Endovascular complications that may occur cause local or systemic effects. We assume that the recovering nerve palsies resulted from extensive swelling and mechanical nerve compression. The local skin and mucous necrosis resulted from toxic effects and extensive swelling of surrounding tissues. Regarding grade III and IV complications, the partial tongue necrosis arose from a bleed that was uncontrollable by conservative methods. The bleed was extensive and came from capillaries of a large area, 
Table 5 Summary of studies on complications of sclerotherapy for head and neck VMs

\begin{tabular}{|c|c|c|c|}
\hline References & $\begin{array}{l}\text { VMs receiving } \\
\text { sclerotherapy }(n)\end{array}$ & Sclerosant & $\begin{array}{l}\text { Complications (per patient/per } \\
\text { treatment) }\end{array}$ \\
\hline Alexander et al. [28] & 26 & Ethanolamine oleate & None \\
\hline Stimpson et al. [29] & 12 & STS & $8.3 \% / 2.7 \%$ \\
\hline Leung et al. [30] & 5 & STS/ethanolamine/doxycycline/ethanol & $15.3 \% / 8.0 \%$ \\
\hline Sachin et el. [31] & 272 & STS/bleomycin/ $N$-butyl cyanoacrylate & $7.7 \% / \mathrm{NR}$ \\
\hline Spence et al. [32] & 17 & Ethanol/bleomycin & $41.2 \% / \mathrm{NR}$ \\
\hline Hu et al. [33] & 91 & Ethanol & $9.9 \% / 3.1 \%$ (only facial paralysis reported) \\
\hline Su et al. [34] & 60 & Ethanol & NSC \\
\hline Wang et al. [35] & 23 & Ethanol & NSC \\
\hline Glade et al. [26] & 13 & STS/ethanol & $7.7 \% / 4.2 \%$ \\
\hline Rosbe KW et al. [36] & 10 & STS & NSC \\
\hline Lee et al. [27] & 87 & Ethanol & $4.6 \% / \mathrm{NR}$ \\
\hline Liu et al. [37] & 23 & Ethanol/pingyangmycin & No skin necrosis or nerve damage \\
\hline Kaji et al. [38] & 73 & Ethanolamine oleate & $61.4 \% / \mathrm{NR}$ \\
\hline Zhi et al. [39] & 82 & Pingyangmycin & NSC \\
\hline Chen et al. [40] & 16 & OK-432/pingyangmycin & $18.8 \% / \mathrm{NR}$ \\
\hline Bonan et al. [41] & 6 & Monoethanolamine & $33.3 \% / \mathrm{NR}$ \\
\hline Kim et al. [42] & 29 & Ethanolamine oleate & $6.9 \% / \mathrm{NR}$ \\
\hline Johnson et al. [43] & 7 & Ethanol & $14.3 \% / \mathrm{NR}$ \\
\hline Berenguer et al. [8] & 40 & Ethanol/STS & $\begin{array}{l}\text { Blistering } 50 \% \text {; Ulceration } 13 \% \text {; Infection } \\
7.5 \% \text {; } \\
\text { Hemoglobinuria } 28 \% \text {; Facial paresis } 5 \% \text {; } \\
\text { Vocal cord paralysis } 2.5 \%\end{array}$ \\
\hline Siniluoto et al. [25] & 38 & STS & $2.6 \%$ (only severe complications reported)/NR \\
\hline Current study & 75 & $\begin{array}{l}\text { STS/polidocanol/bleomycin/ } \\
\text { ethanol/doxycyclin }\end{array}$ & $17.3 \% / 10.0 \%$ \\
\hline
\end{tabular}

STS sodium tetradecyl sulfate, NR not reported, NSC no severe complications

making it difficult to manage. The endovascular treatment was the best available in this emergency case. The tongue necrosis probably resulted from both sclerotherapy and injection of embolizing particles. We deduce that the partial maxilla necrosis developed from sclerosant agent escape into an artery, leading to local thrombosis and tissue ischemia. The mechanisms of the temporal and frontal skin and muscle necrosis with facial nerve palsy remain unclear; we suggest a toxic effect from STS (Table 4).

Choice of the most effective and the safest sclerosant remains challenging. Using mainly detergent sclerosants and only rarely ethanol and bleomycin, we found no statistical difference between sclerosants in regards to risk for complications. Others have reported ethanol to be the most effective but also the most toxic sclerosant agent $[8,46]$, carrying the risk for the most serious side-effects. Many centers, including ours, now prefer the detergent sclerosants such as STS or polidocanol [1, 8, 47]. We found STS and polidocanol to be safe, causing on average fewer complications. We injected only one VM solely with ethanol, later combining ethanol with other sclerosants to enhance the response. Even in combination, ethanol resulted in proportionally more complications (Table 3). Recently developed ethanol gel may provide a solution to diminish ethanol's side-effects by avoiding the toxic systemic leak [48]. Bleomycin was rarely injected, but was involved in relatively many cases with complications. These VMs did, however, occur mostly in very confined and demanding areas. We treated only a few patients with ethanol or bleomycin, and so cannot draw definitive conclusions. A recent review article on sclerotherapy reported that ethanol caused the most skin damage and nerve injuries, as well as serious systemic side-effects [20]. They also found that ethanolamine oleate was considered the most effective sclerosant but produced the highest rate of muscle and renal damage [20]. STS, polidocanol, and bleomycin were used less often, and showed proportionally less complications. Differences between these agents were, however, statistically insignificant [20]. The safety of detergent sclerosants thus warrants further investigations. 
Limitations of our study include its retrospective nature. Recording of treatment response was challenging, as each patient was treated individually without systematic outcome scaling. Patient number in this study was relatively high compared with previous studies, but nevertheless was too low to achieve statistically significant differences between patients and between sclerosants. Moreover, the entire procedure from initial VM diagnosis to successful treatment outcome was developing markedly during our study period (2007-2013). Our MDT's clinical and technical experience has improved tremendously, leading to a more established treatment protocol and a positive learning curve.

\section{Conclusion}

Sclerotherapy constitutes an important treatment method for head and neck VMs. VM characteristics and technical features that predispose to complications call for further investigation. Bearing in mind potential risks, the MDT must evaluate indications for sclerotherapy thoroughly. Choosing the most effective and the safest treatment method for each VM patient demands careful multidisciplinary assessment and therefore remains challenging.

Acknowledgments We kindly acknowledge the members of our MDT for their comments regarding this paper. We also thank our statistician Timo Pessi for his help with objective statistical analysis and our language editor Carol Norris for her critical reading. We thank Helsinki University Central Hospital and the Finnish Otorhinolaryngological Society for their support to this study. Financial support and funding: Helsinki University Central Hospital, The Finnish Otorhinolarynological Society.

Conflict of interest None.

\section{References}

1. Mulliken JB, Fishman SJ, Burrows PE (2000) Vascular anomalies. Curr Probl Surg 37(8):517-584

2. Vikkula M, Boon LM, Mulliken JB (2001) Molecular genetics of vascular malformations. Matrix Biol 20(5-6):327-335

3. Mounayer C, Wassef M, Enjolras O, Boukobza M, Mulliken JB (2001) Facial "glomangiomas": large facial venous malformations with glomus cells. J Am Acad Dermatol 45(2):239-245

4. Vikkula M, Boon LM, Carraway KL 3rd et al (1996) Vascular dysmorphogenesis caused by an activating mutation in the receptor tyrosine kinase TIE2. Cell 87(7):1181-1190

5. Dubois J, Garel L (1999) Imaging and therapeutic approach of hemangiomas and vascular malformations in the pediatric age group. Pediatr Radiol 29(12):879-893

6. Dubois J, Soulez G, Oliva VL, Berthiaume MJ, Lapierre C, Therasse E (2001) Soft-tissue venous malformations in adult patients: imaging and therapeutic issues. Radiographics 21(6):1519-1531

7. Legiehn GM, Heran MK (2008) Venous malformations: Classification, development, diagnosis, and interventional radiologic management. Radiol Clin North Am 46(3):545-597
8. Berenguer B, Burrows PE, Zurakowski D, Mulliken JB (1999) Sclerotherapy of craniofacial venous malformations: Complications and results. Plast Reconstr Surg 104(1):1-11 (discussion 12-5)

9. Boukobza M, Enjolras O, Guichard JP et al (1996) Cerebral developmental venous anomalies associated with head and neck venous malformations. AJNR Am J Neuroradiol 17(5):987-994

10. Steiner F, FitzJohn T, Tan ST (2013) Surgical treatment for venous malformation. J Plast Reconstr Aesthet Surg 66(12):1741-1749

11. Hein KD, Mulliken JB, Kozakewich HP, Upton J, Burrows PE (2002) Venous malformations of skeletal muscle. Plast Reconstr Surg 110(7):1625-1635

12. Lee BB, Bergan JJ (2002) Advanced management of congenital vascular malformations: a multidisciplinary approach. Cardiovasc Surg 10(6):523-533

13. Buckmiller LM (2004) Update on hemangiomas and vascular malformations. Curr Opin Otolaryngol Head Neck Surg 12(6):476-487

14. Werner JA, Lippert BM, Hoffmann P, Rudert H (1995) Nd: YAG laser therapy of voluminous hemangiomas and vascular malformations. Adv Otorhinolaryngol 49:75-80

15. Wimmershoff MB, Landthaler M, Hohenleutner U (1999) Percutaneous and combined percutaneous and intralesional nd: YAG-laser therapy for vascular malformations. Acta Derm Venereol 79(1):71-73

16. Burrows PE (2013) Endovascular treatment of slow-flow vascular malformations. Tech Vasc Interv Radiol 16(1):12-21

17. Lee BB, Do YS, Byun HS, Choo IW, Kim DI, Huh SH (2003) Advanced management of venous malformation with ethanol sclerotherapy: mid-term results. J Vasc Surg 37(3):533-538

18. Tachibana K, Kobayashi S, Kojima T, Kaseno S, Kemmotsu O (2004) Pulmonary emboli in sclerotherapy for peripheral vascular malformations under general anesthesia; a report of two cases. Masui 53(6):645-649

19. Barranco-Pons R, Burrows PE, Landrigan-Ossar M, Trenor CC 3rd, Alomari AI (2012) Gross hemoglobinuria and oliguria are common transient complications of sclerotherapy for venous malformations: review of 475 procedures. AJR Am J Roentgenol 199(3):691-694

20. Qiu Y, Chen H, Lin X, Hu X, Jin Y, Ma G (2013) Outcomes and complications of sclerotherapy for venous malformations. Vasc Endovascular Surg 47(6):454-461

21. Dindo D, Demartines N, Clavien PA (2004) Classification of surgical complications: a new proposal with evaluation in a cohort of 6336 patients and results of a survey. Ann Surg 240(2):205-213

22. Clavien PA, Sanabria JR, Strasberg SM (1992) Proposed classification of complications of surgery with examples of utility in cholecystectomy. Surgery 111(5):518-526

23. Clavien PA, Barkun J, de Oliveira ML et al (2009) The ClavienDindo classification of surgical complications: five-year experience. Ann Surg 250(2):187-196

24. Kollipara R, Dinneen L, Rentas KE et al (2013) Current classification and terminology of pediatric vascular anomalies. AJR Am J Roentgenol 201(5):1124-1135

25. Siniluoto TM, Svendsen PA, Wikholm GM, Fogdestam I, Edstrom S (1997) Percutaneous sclerotherapy of venous malformations of the head and neck using sodium tetradecyl sulphate (sotradecol). Scand J Plast Reconstr Surg Hand Surg 31(2):145-150

26. Glade RS, Richter GT, James CA, Suen JY, Buckmiller LM (2010) Diagnosis and management of pediatric cervicofacial venous malformations: retrospective review from a vascular anomalies center. Laryngoscope 120(2):229-235

27. Lee IH, Kim KH, Jeon P et al (2009) Ethanol sclerotherapy for the management of craniofacial venous malformations: the interim results. Korean J Radiol 10(3):269-276 
28. Alexander MD, McTaggart RA, Choudhri OA, Marcellus ML, Do HM (2013) Percutaneous sclerotherapy with ethanolamine oleate for venous malformations of the head and neck. J Neurointerv Surg. doi:10.1136/neurintsurg-2013-010924

29. Stimpson P, Hewitt R, Barnacle A, Roebuck DJ, Hartley B (2012) Sodium tetradecyl sulphate sclerotherapy for treating venous malformations of the oral and pharyngeal regions in children. Int J Pediatr Otorhinolaryngol 76(4):569-573

30. Leung M, Leung L, Fung D et al (2013) Management of the lowflow head and neck vascular malformations in children: The sclerotherapy protocol. Eur J Pediatr Surg. doi:10.1055/s-00331354585

31. Sachin K, Rashmi S, Manish S, Siddhartha W, Uday L (2013) Haemangiomas and venous malformations of the head and neck: a retrospective analysis of endovascular management in 358 patients. Indian J Plast Surg 46(1):109-116

32. Spence J, Krings T, TerBrugge KG, Agid R (2011) Percutaneous treatment of facial venous malformations: a matched comparison of alcohol and bleomycin sclerotherapy. Head Neck 33(1):125-130

33. Hu X, Chen D, Jiang C et al (2011) Retrospective analysis of facial paralysis caused by ethanol sclerotherapy for facial venous malformation. Head Neck 33(11):1616-1621

34. Su L, Fan X, Zheng L, Zheng J (2010) Absolute ethanol sclerotherapy for venous malformations in the face and neck. J Oral Maxillofac Surg 68(7):1622-1627

35. Wang YA, Zheng JW, Zhu HG, Ye WM, He Y, Zhang ZY (2010) Sclerotherapy of voluminous venous malformation in head and neck with absolute ethanol under digital subtraction angiography guidance. Phlebology 25(3):138-144

36. Rosbe KW, Hess CP, Dowd CF, Frieden IJ (2010) Masseteric venous malformations: diagnosis, treatment, and outcomes. Otolaryngol Head Neck Surg 143(6):779-783

37. Liu Y, Liu D, Wang Y, Zhang W, Zhao F (2009) Clinical study of sclerotherapy of maxillofacial venous malformation using absolute ethanol and pingyangmycin. J Oral Maxillofac Surg 67(1):98-104

38. Kaji N, Kurita M, Ozaki M et al (2009) Experience of sclerotherapy and embolosclerotherapy using ethanolamine oleate for vascular malformations of the head and neck. Scand J Plast Reconstr Surg Hand Surg 43(3):126-136

39. Zhi K, Wen Y, Li L, Ren W (2008) The role of intralesional pingyangmycin in the treatment of venous malformation of facial and maxillary region. Int J Pediatr Otorhinolaryngol 72(5):593-597

40. Chen WL, Yang ZH, Bai ZB, Wang YY, Huang ZQ, Wang YJ (2008) A pilot study on combination compartmentalisation and sclerotherapy for the treatment of massive venous malformations of the face and neck. J Plast Reconstr Aesthet Surg 61(12):1486-1492

41. Bonan PR, Miranda Lde P, Mendes DC, de Paula AM, Pego SP, Martelli-Junior H (2007) Effectiveness of low flow vascular lesions sclerosis with monoethanolamine: report of six cases. Med Oral Patol Oral Cir Bucal 12(7):E524-E527

42. Kim KH, Sung MW, Roh JL, Han MH (2004) Sclerotherapy for congenital lesions in the head and neck. Otolaryngol Head Neck Surg 131(3):307-316

43. Johnson PL, Eckard DA, Brecheisen MA, Girod DA, Tsue TT (2002) Percutaneous ethanol sclerotherapy of venous malformations of the tongue. AJNR Am J Neuroradiol 23(5):779-782

44. Chen G, Cai X, Ren JG, Jia J, Zhao YF (2013) Unexpected development of tongue squamous cell carcinoma after sclerotherapy for the venous malformation: a unique case report and literature review. Diagn Pathol 8(1):182

45. Omary RA, Bettmann MA, Cardella JF et al (2003) Quality improvement guidelines for the reporting and archiving of interventional radiology procedures. J Vasc Interv Radiol 14(9 Pt 2):S293-S295

46. Shireman PK, McCarthy WJ, Yao JS, Vogelzang RL (1997) Treatment of venous malformations by direct injection with ethanol. J Vasc Surg 26(5):838-844

47. Kok K, McCafferty I, Monaghan A, Nishikawa H (2012) Percutaneous sclerotherapy of vascular malformations in children using sodium tetradecyl sulphate: the birmingham experience. J Plast Reconstr Aesthet Surg 65(11):1451-1460

48. Schumacher M, Dupuy P, Bartoli J et al (2011) Treatment of venous malformations: first experience with a new sclerosing agent: a multicenter study. Eur J Radiol 80(3):e366-e372 